\title{
RESENHA
}

\section{UM “ENTENDIMENTO DO ENTENDIMENTO”: OLHAR SOBRE OSABER LOCAL $^{1}$}

\author{
Miriam Espindula dos Santos ${ }^{2}$
}

Agora somos todos nativos.

A vida é uma tradução

\section{INICIANDO A CONVERSA}

Primeiramente quero justificar minha opção por fazer uma síntese-resenha do livro 0 Saber Local: novos ensaios em antropologia interpretativa, de Clifford Geertz. A escolha se deu pela inquietação que o mesmo provocou no momento de sua leitura, o referido ensaio contribuiu de forma significante para o meu processo de (in) maturação acadêmica, pessoal e de pesquisadora. A intenção é destacar os pontos mais relevantes do livro, lançar um olhar sobre algumas questões problematizadas pelo autor. Apesar de não utilizar a hermenêutica interpretativa proposta por Geertz em minha pesquisa, a mesma possibilitou muitas ideias acerca de como proceder enquanto pesquisadora, no trato que devo ter para com o meu objeto, um trato respeitoso, atencioso, aberto, com um olhar afinado para as questões que o cerca, bem como o uso de analogias para analisar determinados fatos. Destaco que o meu olhar sobre este ensaio também reflete as discussões calorosas que realizamos em sala de aula acerca do mesmo, bem como dos momentos em que analisamos os projetos de pesquisas dos colegas da turma, apesar de não me deter neste aspecto. Assim sendo, vou seguir basicamente a divisão proposta pelo ensaísta nesta obra, refletindo acerca do que mais me inquietou neste ensaio.

$\mathrm{Na}$ introdução, Geertz explicita suas posições teóricas ressaltando que o ensaio é uma tentativa de "entendimento do entendimento" (p. 10), de "desprovincialização intelectual" (p.9), afirma que

existe um sistema na persistência, que todas estas perguntas, com objetivos tão diversos, são inspiradas por uma visão estabelecida de como devemos proceder para construir um relato da estrutura imaginativa de uma sociedade. (p. 11)

Em tal afirmação o autor deixa claro que na forma como pesquisamos há um "sistema", uma lógica, uma "visão estabelecida" e que a mesma direciona o modo como pesquisamos. Contudo, logo a seguir salienta que, "se a visão é estabelecida a maneira como ela é traduzida em realidade prática, para que possa funcionar, não o é" (p. 11). Abre-se então a possibilidade

\footnotetext{
${ }^{1}$ Este texto foi elaborado como pré-requisito da disciplina Pesquisa em Educação, sob a orientação do prof. Matheus Zica, do PPGE/UFPB.

${ }^{2}$ Mestranda em Educação - UFPB.
} 
de inovação, de direcionarmos nosso olhar para outros caminhos menos convencionais, "utilizar desvios" (p. 12) na tentativa de traduzir a realidade. É justamente nesta "tradução" que o autor se detém durante todo o ensaio, ou seja, entender os entendimentos "diferentes do nosso" (p. 11). O que não devemos é delimitar, de forma aguda, nossa percepção, cerceá-la seria um erro no que tange a pesquisa, ao contrário devemos estar abertos e dispostos a enveredar ou "passear por ruas paralelas" e assim nos apropriarmos o máximo possível das questões que orbitam em torno do nosso objeto.

Ainda na introdução traz alguns destaques com relação às mudanças que ocorrem nas ciências sociais, potencializadas segundo o autor, por alguns teóricos ${ }^{3}$, e como este novo olhar impacta a mesma. Neste complexo movimento a "ciência da sociedade" está cada vez "mais pluralista" e promove a "desprovincialização intelectual", oxigenando a forma como se traduz o mundo.

No capítulo 1, "Mistura dos gêneros: a reconfiguração do pensamento social" (p. 25), Geertz registra que há uma "mudança no próprio sistema de mapear" (p. 26). Estamos, de acordo com o autor, construindo novas formas de interpretação do mundo, aproximando-nos cada vez mais desta saudável "mistura de gêneros" para analisar nossos objetos. Não há um abandono as "convenções de interpretação" e sim uma urgente necessidade de diversificar as formas de pesquisar/ traduzir a realidade para "adaptar-nos a uma situação ao mesmo tempo fluida, plural, descentralizada, e inerradicavelmente desorganizada" (p. 26). Os cientistas sociais, "dada a nova dispersão de gêneros", e devido a complexidade do tecido social, têm mais liberdade para "satisfazer percepções externas sobre aquilo que devem ou não fazer" ( $p$. 27), encontraram-se num "sistemático desfazer de malas no mundo conceptual". Neste movimento os "estudos sociais estão adotando um novo estilo de discurso" e os "instrumentos do raciocínio estão se modificando" (p. 28). Como exemplo dessa nova "remoldagem" (p. 28) cita a analogia com jogos, com dramas, com textos. Ressalta ainda que, o que interessa "não é saber como todas estas formas híbridas vão se juntar para formar alguma teoria esplêndida, mas sim o porquê de toda esta fermentação" (p. 39). Segundo Geertz a "refiguração da teoria social" promoverá ou "representará um dia, uma mudança radical na noção que hoje temos do conhecimento, alterando não tanto a definição do que é conhecimento, mas principalmente a definição daquilo que queremos saber" (p. 39). Coadunando com a perspectiva do autor, trago um recorte do texto o qual afirma que "já não é possível expressar a relação entre o pensamento e a ação na vida social, nem em termos de sabedoria, nem em termos de habilidade", tal impossibilidade também reflete a possibilidade de lançarmos uma outra lente e ampliarmos nossa forma de traduzir a realidade. Em suma o autor, neste capítulo, expõe os motivos que impulsionaram a mistura de gêneros, cita alguns exemplos, apresentando os pontos positivos, lacunas, usos, desafios e impactos dessa mudança para a teoria social e para as ciências sociais.

No segundo capítulo, a saber, "Descoberto na tradução: a história social da imaginação moral" (p. 41), Geertz traz, do meu ponto de vista, uma rica argumentação e questionamentos importantes acerca de como construímos nosso imaginário social. Neste, o autor reflete sobre como a tradução de formas de manifestação cultural são realizadas e como as implicações das mesmas afetam nossas vidas e imaginário. Para o ensaísta os "produtos significativos da imaginação humana [...] são testemunhos igualmente poderosos da crença reconfortante de que somos todos iguais e da desconfiança preocupante de que não somos" (p. 47-48). Alega que há "instabilidades" e que as mesmas influenciam no modo como lemos e apreendemos a nossa cultura e as demais. Tais "instabilidades" ou uma "série de instabilidades - de perspectiva, de significado, de julgamento" emergem e estão vinculadas a nossa percepção, quando nos deparamos com outra cultura, com "outra maneira de ser e estar no mundo"

\footnotetext{
${ }^{3}$ Ver p. 9 e 10 .
} 
Caleffi $(2008$, p. 33). Estas, juntamente com a concepção que temos acerca do outro e de como o mesmo deve ser e comportar-se, gera momentos de inquietação e insegurança, quando da análise de determinados fatos. Assim as indagações, inquietações, inseguranças, ou seja, as "instabilidades" vivenciadas no processo da pesquisa fazem parte do ato de pesquisar. Segundo Geertz

Escrever sobre a história social da imaginação moral, ou ensiná-las [...] é tentar penetrar de alguma maneira neste emaranhado de implicações hermenêuticas, localizar com alguma precisão as instabilidades de pensamento e de sentimento que ele produz, e colocá-las em uma moldura social. Tais esforços não serão suficientes para desfazer os nós do emaranhado, nem para remover as instabilidades. Ao contrário, como sugeri, farão com que estes fiquem mais visíveis, e causem maior inquietação. O que fazem, no entanto, ou podem fazer é colocá-los em um contexto inteligível" ( $p$. 51).

Este capítulo provoca uma "fermentação" em nosso ser, pois nos impulsiona a refletir sobre nosso posicionamento moral, ético, religioso, político e cultural. Provoca sentimentos antagônicos, agônicos, confusos uma "desprovincialização intelectual", visto que, a "vida é uma tradução na qual estamos todos perdidos" (p. 50). Então, descobrir-se na tradução é perceber que a outra cultura constitui-se de forma tão peculiar, complexa e legítima quanto à cultura da qual você faz parte. O olhar do pesquisador deve estar afinado para perceber as nuances e peculiaridades desta "outra maneira de ser e estar no mundo", respeitando-a tanto quanto respeita a sua.

Em "Do ponto de vista dos nativos: a natureza do entendimento antropológico" ( $p$. 60), no capítulo terceiro, o ensaísta registra que olhar "do ponto de vista dos nativos" é tentar "captar conceitos que para outras pessoas são de experiência-próxima e fazê-los de uma forma tão eficaz que nos permita estabelecer uma conexão esclarecedora com os conceitos de experiência-distante". Tal exercício requer momentos de afastamento e de encharcamento com o objeto, por isso segundo o autor é "uma tarefa tão delicada" (p. 62). O caminho sugerido é o de buscar compreender como as pessoas de uma determinada cultura concebem a si mesmas, "analisando as formas simbólicas" que são utilizadas por elas para representarem a si mesmas e aos outros. O referido destaca que o "conceito de pessoa" é um "veículo excelente" para passear e se apropriar do que "passa pela mente alheia" (p.63). Geertz ainda afirma que "para entender as concepções alheias é necessário que deixemos de lado nossa concepção, e busquemos ver as experiências de outros com relação à sua própria concepção do "eu"' (p. 64). É, descoberto na tradução, tentar observar como a outra cultura se constitui. Nesse intuito o ensaísta cita algumas análises que realizou, como exemplos de como, a constituição de quem somos e a maneira como nos concebemos, é algo complexo, íntimo e depende da cultura a qual pertence. O primeiro exemplo, citado pelo autor advém de Java, orbita em torno de como o eu é concebido por forças internas, "mundo interior de emoção contida", e externa, "um mundo exterior de comportamento estruturado" (p. 66). Estas forças organizam o "modus operandi" da sociedade em Java. A "concepção do eu" neste caso é "bifurcada, sendo uma de suas partes constituída por sentimentos meio sem gestos, e outra por gestos meios sem sentimentos" (p. 65-66). Um segundo exemplo é o citado em Bali, que o autor denomina de "teatro do status" e que define o eu dos balineses. Geertz argumenta que os "balineses tem pelo menos meia dúzia de títulos principais, atribuídos, fixos e absolutos que uma pessoa usaria para designar outra (ou, é claro a si mesma) como parte de seu grupo". 
Estes "marcadores" são utilizados para definir "alguém como ponto determinado em uma estrutura fixa ocupante temporário de um locus cultural" (p. 67). Outro exemplo seria o das "pessoas contextualizadas" do Marrocos. De acordo com referido a "contextualização social das pessoas é difusa, e na sua maneira curiosamente não metódica acaba sendo sistemática [...] sua identidade é atributo que tomam emprestado no cenário que os rodeia". Ressalta, ainda, que tanto em Java quanto em Bali a constituição do eu é algo atribuído e encenado no teatro social e que ao privado resta à segregação. Para o autor o Oriente Médio apresenta um "sistema mosaico de organização social", este concebido como "fragmentos de formas e cores diferentes que são encaixados irregularmente para gerar um desenho global complexo, no qual a diferença individual de cada fragmento permanece intacta" (p. 71). Nesse processo dinâmico e complexo o ensaísta destaca que entender o entendimento "é um bordejar dialético contínuo, entre o menor detalhe nos locais menores, e a mais global das estruturas globais, de tal forma que ambos possam ser observados simultaneamente" (p. 73). É "interpretar um poema" (p. 74).

No capítulo quatro, "O senso comum como um sistema cultural" (p. 77), percebemos o senso comum como um conhecimento que está arraigado nas mais variadas culturas. Este se constitui, ao mesmo tempo e com a mesma legitimidade, com que se constitui a cultura de uma determinada sociedade. Como construção social depende do contexto, do tempo, do lugar e se expressa de forma natural. Como "forma cultural presente em qualquer sociedade" (p. 89) o senso comum deve ser considerado como instrumento potencializador de tradução de culturas. Para Geertz, o "único procedimento que nos resta, portanto, é o de tomarmos o desvio específico de evocar o som e os vários tons que são geralmente reconhecidos como pertencentes ao senso comum [...] para poder lembrar às pessoas aquilo que já sabem", pois o conhecimento cotidiano está tão "diante dos nossos olhos que é impossível encontrá-los" (p. 96).

Ao abordar a "A arte como um sistema cultural" (p. 98), no capítulo cinco, o autor explicita que a arte, manifestada em forma de pintura, poema ou poesia representa e expressa à cultura de uma sociedade, sua "maneira de ser e estar no mundo" (Caleffi, 2008, p. 33), visto que o "sentimento que um povo tem [...] surge em vários outros segmentos da cultura deste povo" (p. 100). Segundo Geertz a "arte e os instrumentos para entendê-la são feitos na mesma fábrica" sociocultural, por isso é interessante na pesquisa considerar a "história natural de indicadores e símbolos", observar o que os tornam relevantes, pois eles "desempenham um papel na vida de uma sociedade" (p. 122). Para o referido se "existe algo em comum entre todas as artes" é que "em qualquer lugar do mundo certas atividades parecem estar especificamente destinadas a demonstrar que as ideias são visíveis, audíveis [...] e tactíveis", ou seja, permitem uma comunicação "reflexiva" e interpretativa.

Acerca do sexto capítulo, "Centros, reis e carisma: reflexões sobre o simbolismo do poder" (p. 125) o ensaísta analisa como a mística que envolve o poder e os centros de poder é constituída, organizada e perpetuada por figuras carismáticas. Tais figuras atuam no cenário social de maneira emblemática, reproduzem e carregam os símbolos da "autoridade política" que de acordo com o autor "exigem uma estrutura cultural em que se definir e fazer asserções" (p. 145-146). A lente para olhar e compreender tal cenário depende da "percepção de que embora mudem tanto a estrutura como as expressões da vida social, não mudam as necessidades internas que lhes dão vida" (p. 145). Há, na sociedade, uma necessidade de representação do centro de poder, de legitimá-lo, um "poder sagrado que é inerente à autoridade central" (p. 149) para que o mesmo possa ser exercido de forma a contemplar as demandas desta sociedade, de representá-la.

Em "Como pensamos hoje: a caminho de uma etnografia do pensamento moderno" ( $p$. 150), no capítulo sete, a proposta do autor é "examinar o que é precisamente que pensamos sobre o pensamento" (p. 151), realizar uma "etnografia do pensamento" (p. 157). Na análise 
de algumas teorias do pensamento ${ }^{4}$ infere que o "pensamento é espetacularmente múltiplo como um produto, e maravilhosamente singular como um processo", o que resulta em entendermos que a compreensão do mesmo depende da qualidade de nossa "tradução", pois a "questão é descobrir como é que os outros, além-mar ou do outro lado do corredor, organizam seu universo de significados" (p. 154). Para Geertz o pensamento "deve ser compreendido [...], através de uma descrição daquele mundo específico onde este pensamento faz algum sentido" juntamente com as "formas simbólicas" praticadas nele.

No último capítulo do ensaio, "O saber local: fatos e leis em uma perspectiva comparativa" (p.169), o autor intenciona analisar os pontos convergentes das áreas de conhecimento, antropologia e direito, "um ir e vir hermenêutico entre os dois campos [...] a fim de formular as questões morais, políticas e intelectuais que são importantes para ambos" (p.171), é nessa perspectiva metodológica que o autor desenvolve sua análise. Relata que a complexidade social está tornando os julgamentos também complexos, ao mesmo tempo, observa-se que as ideias mercadológicas tais como: objetivar, economizar, simplificar, otimizar o direito está crescendo, urge realizar "uma justiça sem complicações". A "simplificação dos fatos" de acordo com o ensaísta é um "processo inevitável e necessário" nas questões jurídicas, pois o direito não busca a "estória real e completa" dos fatos (p. 174), o que demanda que estes sejam representados. Como o direito é concebido de forma diferente "de um lugar ao outro, de uma época a outra, então os que os olhos veem também se modifica" (p. 175), daí "o problema fundamental é descobrir como representar aquela representação" (p. 176). Neste "processo de representação" (p. 175) os dois termos ou categorias "se/então" e "como/portanto" são imprescindíveis para formular uma representação, é unir o "se/então" da existência, em sua visão local, com o "como/portanto" da experiência, segundo a percepção também local. O que nos leva a inferir que, sejam nas análises antropológicas ou na "sensibilidade jurídica" (p.177) do direito, bem como nas análises de outras áreas de conhecimento, é importante estarmos atentos para percebermos as peculiaridades de cada cultura e suas estruturas socioculturais. A tradução da mesma depende desta qualidade do olhar, e é através desta tradução que outras pessoas que terão acesso ao nosso trabalho e, consequentemente, acessam as outras "maneira de ser e estar no mundo".

\section{Algumas considerações}

Espelhando-me no excelente manejo, que Geertz demonstrou com o uso de analogias, vou tentar utilizar três verbos, que me vieram à mente ao fim desta leitura, para resumir, por agora, minha percepção acerca do presente ensaio, a saber: atingir, provocar e evocar, que expressam de forma sintética, porém com muitos impactos, a ação das proposições do autor. A estes articulo os adjetivos sensibilidade, racionalidade ousadia, respectivamente. Desta forma, o presente ensaio atinge a sensibilidade, em sua forma e percepção; provoca um abalo sísmico na racionalidade, em muitos aspectos sedimentada, delimitada e amplia os horizontes do nosso pesquisar; e, evoca a ousadia no nosso fazer enquanto pesquisadores, pois possibilita o trânsito por "desvios" e "ruas paralelas". Além de ressaltar, em vários momentos, a necessidade de o pesquisador estar aberto e atento no processo de entender o entendimento das culturas através de uma "tradução" ou hermenêutica interpretativa, e assim possa apreender as especificidades e peculiaridades de tais culturas, percebendo-as tão importantes e legítimas quanto a sua. Senti-me nativa, descoberta na tradução!

\footnotetext{
${ }^{4}$ Ver p. 153 e 154.
} 


\section{REFERÊNCIAS}

CALEFFI, Paula. Educação autóctone nos séculos XVI ao XVIII ou Américo Vespúcio tinha razão?. In: História e memórias da educação no Brasil, Vol. 1 Séculos XVI- XVIII. Maria Stephanou, Maria Helena Camara Bastos (org.). 3. Ed. - Petrópolis, RJ: Vozes, 2008.

GEERTZ, Clifford. O saber local: novos ensaios em antropologia interpretativa. Tradução de Vera Joscelyne. 12 ed. Petrópolis, RJ: Vozes, 2012. 